\title{
ANÁLISE BACTERIOSCÓPICA E MICROBIOLÓGICA INTRAOPERATÓRIA DE PACIENTES SUBMETIDOS A TRATAMENTO CIRÚRGICO DE ESCOLIOSE IDIOPÁTICA DO ADOLESCENTE
}

\author{
INTRAOPERATIVE BACTERIOSCOPICAL AND MICROBIOLOGICAL ANALYSIS IN PATIENTS \\ UNDERGOING A SURGICAL TREATMENT OF ADOLESCENT IDIOPATHIC SCOLIOSIS
}

\section{ANÁLISIS BACTERIOSCÓPICA Y MICROBIOLÓGICA INTRAOPERATORIA DE PACIENTES SOMETIDOS AL TRATAMIENTO QUIRÚRGICO DE LA ESCOLIOSIS IDIOPÁTICA DEL ADOLESCENTE}

Guilherme Galvão Barreto Carneiro ${ }^{1}$, José Lucas Batista Júnior² ${ }^{2}$ Charbel Jacob Júnior ${ }^{2}$, Igor Machado Cardoso ${ }^{3}$,

Rafaela Freitas Cutini Detoni ${ }^{4}$, Rodrigo Rezende ${ }^{5}$

\section{RESUMO}

Objetivo: Avaliar a presença e o crescimento microbiológico no sítio operatório em pacientes submetidos a tratamento cirúrgico de escoliose idiopática do adolescente na primeira, segunda e terceira hora de cirurgia. Casuística e Método: Estudo prospectivo, de caráter descritivo e comparativo, sendo avaliados 34 pacientes portadores de escoliose idiopática do adolescente com indicação cirúrgica, analisando a contaminação no sítio cirúrgico através da bacterioscopia e cultura óssea na primeira, segunda e terceira hora de cirurgia. Resultados: Houve bacterioscopia positiva crescente entre a primeira e a segunda hora de cirurgia. A cultura confirma a colonização da ferida operatória, crescente entre as horas analisadas. Conclusões: O tempo cirúrgico prolongado está diretamente relacionado ao maior crescimento microbiológico no sítio cirúrgico de pacientes submetidos à correção de escoliose vertebral.

Descritores: Microbiologia; Escoliose; Infecção.

\begin{abstract}
Objective: To evaluate the presence and microbiological growth in the operative site in patients undergoing surgical treatment of idiopathic scoliosis in the spine of first, second and third hours of surgery. Methods: Prospective, descriptive and comparative study that evaluated 34 patients with adolescent idiopathic scoliosis with surgical indication, analyzing contamination at the surgical site through Gram staining and bone culture in the first, second and third hour of surgery. Results: There were positive bacteroscopical growing between the first and the second hour of surgery. The culture confirms the colonization of the wound, increasing between the hours analyzed. Conclusions: The prolonged surgical time is directly related to higher microbial growth in the surgical site in patients undergoing spinal scoliosis correction.

Keywords: Microbiology; Scoliosis; Infection.

RESUMEN

Objetivo: Evaluar la presencia y el crecimiento microbiológico, en el área operatoria, en pacientes sometidos a tratamiento quirúrgico de escoliosis idiopática del adolescente en la primera, segunda y tercera hora de la intervención quirúrgica. Casuística y Método: Estudio prospectivo, de carácter descriptivo y comparativo, habiendo sido evaluados 34 pacientes portadores de escoliosis idiopática del adolescente con indicación quirúrgica, siendo analizada la contaminación en el área de la operación quirúrgica mediante la bacterioscopia y el cultivo óseo en la primera, segunda y tercera hora de la intervención quirúrgica. Resultados: Hubo bacterioscopia positiva creciente entre la primera y la segunda hora de la operación quirúrgica. El cultivo confirmó la colonización de la herida operatoria, siendo creciente entre las horas analizadas. Conclusiones: El tiempo prolongado de la operación quirúrgica está relacionado directamente con el aumento del crecimiento microbiológico en el área quirúrgica de pacientes sometidos a corrección de la escoliosis vertebral.
\end{abstract}

Descriptores: Microbiología; Escoliosis; Infección.

\section{INTRODUÇÃO}

A escoliose idiopática é uma deformidade tridimensional da coluna vertebral de causa desconhecida caracterizada por um desvio no plano frontal maior que 10 graus, contudo, ela também inclui alterações no plano sagital e rotacional. Atinge cerca de 2 a $3 \%$ da população geral e pode ser classificada de acordo com a idade, tipo de curva, localização da curva e grau de estruturação ${ }^{1-4}$.
A Escoliose Idiopática do Adolescente (EIA) é a forma mais comum de escoliose e incide em até $2 \%$ dos adolescentes, com maior prevalência no sexo feminino, tendo como o padrão mais comum as curvas torácicas direitas ${ }^{1-4}$.

A etiologia da EIA permanece obscura. Algumas teorias multifatoriais são postuladas, dentre as quais podemos citar o desvio padrão de crescimento, alterações neuromusculares ou do tecido

1. Médico residente em Ortopedia do Vila Velha Hospital - Vila Velha, ES, Brasil.

2. Ortopedista e Cirurgião da Coluna, Médico assistente do Grupo de Coluna Vertebral do Hospital Santa Casa de Misericórdia de Vitória - Vitória, ES, Brasil.

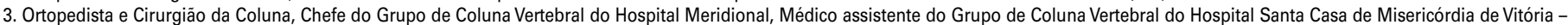
Vitória, ES, Brasil.

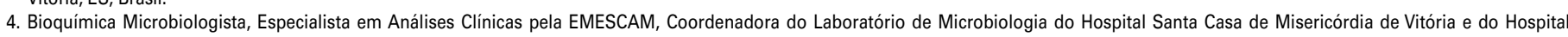
Evangélico de Vila Velha - Vila Velha, ES, Brasil.

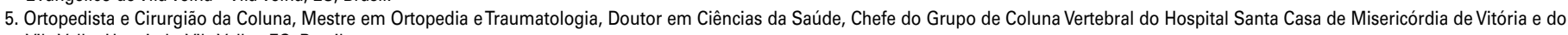
Vila Velha Hospital - Vila Velha, ES, Brasil. 
conjuntivo, crescimento assimétrico dos membros e do tronco, alterações da configuração sagital da coluna vertebral, fatores hereditários e fatores ambientais ${ }^{5,6}$.

As formas de tratamento da EIA podem ser conservadora e cirúrgica. As técnicas conservadoras mais aceitas são a observação e o uso de órteses. O tratamento conservador ainda incluiu a fisioterapia, manipulação e estimulação elétrica, que ainda não teve a eficácia comprovada por falta de evidências científicas ${ }^{7}$.

A indicação de correção cirúrgica da escoliose esta relacionada à magnitude da curva, a deformidade clínica, ao padrão da curva, ao risco de progressão e a maturidade esquelética. Em geral, curvas maiores de $50^{\circ}$ possuem indicação para o tratamento cirúrgico ${ }^{1,7-9}$.

As complicações do tratamento cirúrgico da escoliose podem ser imediatas ou tardias. As complicações imediatas podem ser neurológicas, pulmonares ou vasculares, tardiamente podem surgir infecções e pseudo-artrose ${ }^{10}$.

Dentre as complicações tardias, a infecção representa um desafio para o cirurgião ortopédico, ocorrendo em 1 a 3\% dos casos, sendo o agente etiológico mais comum os estafilococos. Essa complicação pode provocar danos irreversíveis aos pacientes que variam desde a perda da correção até a morte por sepse. Embora a bacteremia seja um fator comum, outros fatores etiológicos devem estar presentes para que a infecção ocorra, portanto, o cirurgião ortopédico deve avaliar o risco de infecção de cada paciente, considerando fatores dependentes tanto do paciente quanto do cirurgião 2,11.

Dentre os fatores dependentes do paciente, destacam-se o estado nutricional e a resposta imunológica, e dentre os fatores dependentes do cirurgião, destacam-se a preparação da pele do paciente, o ambiente da sala de operações e a antibioticoterapia profilática ${ }^{12-14}$.

Tratando-se do ambiente da sala operatória sabemos que o sistema de ventilação ambiente, o tipo de esterilização dos materiais, o número de pessoas na sala cirúrgica, a experiência da equipe médica responsável pelo procedimento e o tempo cirúrgico prolongado podem ser causas de aumento da taxa de infecção ${ }^{15-18}$.

Não encontramos na literatura trabalhos que justifiquem a relação do tempo prolongado da cirurgia de escoliose com o maior índice de infecção. Com isso, objetivamos, no nosso trabalho, estabelecer esta relação através de uma análise bacterioscópica e microbiológica na ferida operatória de pacientes submetidos a tratamento cirúrgico de escoliose idiopática vertebral durante a primeira, segunda e terceira hora de cirurgia.

\section{CASUÍSTICA E MÉTODO}

Realizamos um estudo prospectivo, de caráter descritivo e comparativo, a partir de um levantamento de dados obtidos através de uma análise progressiva do tempo cirúrgico em 34 pacientes portadores de EIA com indicação cirúrgica, sendo 28 do sexo feminino. Foi verificada a contaminação do sitio cirúrgico através de bacterioscopia pelo método de Gram e de cultura de tecido ósseo, analisados na primeira, segunda e terceira hora de cirurgia. Em relação ao tempo cirúrgico, o procedimento durou entre duas e três horas em $64,7 \%$ dos pacientes e em 35,3\% de pacientes teve duração entre três e quatro horas.

As amostras foram coletadas no intra-operatório sendo colhida secreção da musculatura, utilizando swab estéril, para realização da bacterioscopia, e ressecado um fragmento ósseo, para realização da cultura. Todo material foi enviado imediatamente após a coleta para o laboratório, no final de cada hora subseqüente do ato cirúrgico.

O esquema de antibioticoprofilaxia utilizado em nossa Instituição é a administração de cefazolina dois gramas na indução anestésica e manutenção de um grama de oito em oito horas, por período pós-operatório de cinco dias. No decorrer do nosso trabalho não foi alterada a rotina de antibióticoprofilaxia, mesmo após os resultados iniciais do antibiograma e cultura.

Como critérios de inclusão foram selecionados pacientes portadores de escoliose idiopática do adolescente, acompanhados no ambulatório do grupo de coluna da Santa Casa de Vitória, e que apresentavam curvas maiores que $50^{\circ}$ e potencial de crescimento avaliado pelo Risser.

Como critérios de exclusão foram os demais pacientes portadores de EIA sem indicação cirúrgica, outras escolioses que não as idiopáticas do adolescente e os casos de EIA em que não foram coletadas as amostras nos tempos corretos.

\section{RESULTADOS}

Foram avaliados 34 pacientes, sendo 34 na primeira e segunda hora de cirurgia (100\%), e 12 na terceira hora (35,3\%) (Tabela 1).

Em relação ao crescimento bacteriano, observamos uma positividade na bacterioscopia em seis pacientes $(17,6 \%)$ na primeira hora e em 15 pacientes $(44,1 \%)$ na segunda hora. Já na terceira hora do procedimento cirúrgico observamos um crescimento bacteriano em três pacientes (25\%) (Figura 1).

Quando analisamos os resultados da cultura, não observamos, na primeira hora, uma positividade em nenhum paciente (0\%), já na segunda hora, observamos positividade em três pacientes (8,8\%) e, na terceira hora, em três pacientes (25\%) (Figura 2).

Dentre os germes crescentes, os mais comuns foram os estafilococos, sendo encontrados, em dois pacientes, o Staphylococcus sp coagulase negativo, e, em um paciente, o Staphylococcus epidermidis. Os outros germes foram o Bacillus sp e o Acinetobacter iwoffii, presentes em um paciente cada. Em um dos casos foi encontrado um bacilo gram positivo indefinido.

Tabela 1. Número de pacientes avaliados nas horas de cirurgia.

\begin{tabular}{c|c|c|c}
\hline & $\mathbf{1}^{\text {a }}$ hora & $\mathbf{2}^{\text {a }}$ hora & $\mathbf{3}^{\text {a }}$ hora \\
\hline Número de pacientes & $34(100 \%)$ & $34(100 \%)$ & $12(35,3 \%)$ \\
\hline
\end{tabular}

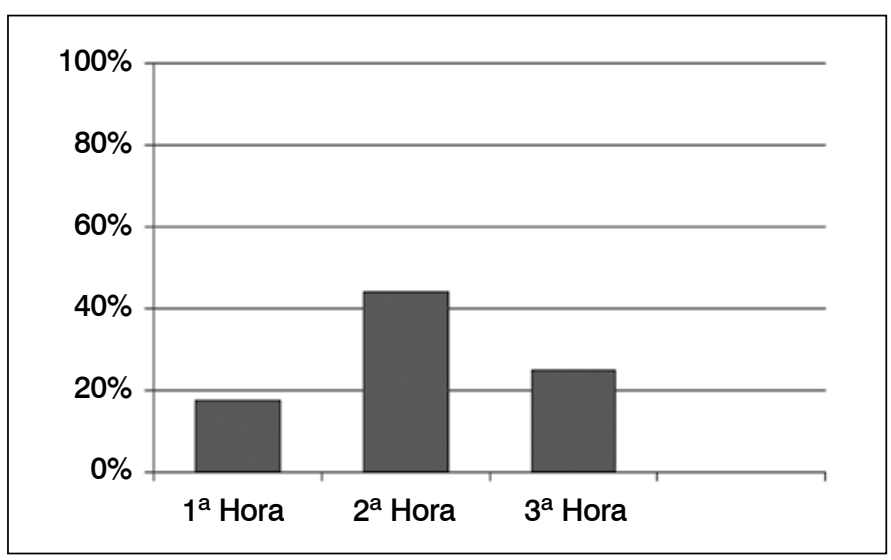

Figura 1. Avaliação da bacterioscopia no decorrer das três primeiras horas de cirurgia

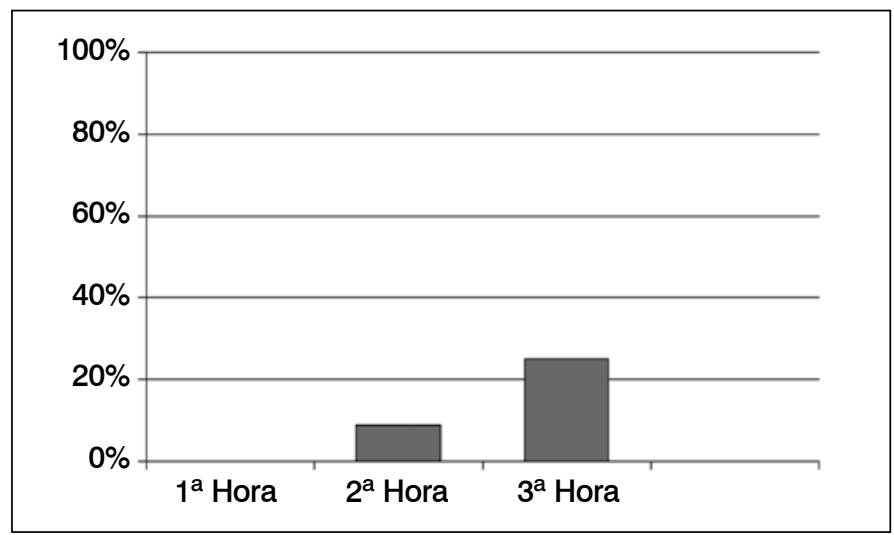

Figura 2. Avaliação da positividade da cultura no decorrer das três primeiras horas de cirurgia. 


\section{DISCUSSÃO}

A principal complicação pós-operatória nas cirurgias ortopédicas é a infecção da ferida cirúrgica. Muitos fatores como grau de nutrição dos pacientes, tipo de esterilização de materiais, número de pessoas na sala cirúrgica e experiência da equipe médica responsável pelo procedimento podem ser causas de aumento da taxa de infecção ${ }^{15-18}$.

Encontramos na literatura diversos trabalhos que correlacionaram positivamente o tempo cirúrgico à taxa de infecção, porém nenhum trabalho analisou diretamente a presença bacteriana e 0 seu crescimento durante o ato operatório.

Weiss e Goodall ${ }^{19}$ realizaram uma revisão sistemática na literatura, avaliando 287 trabalhos sobre as complicações da cirurgia de escoliose, dentre as quais, a infecção, correlacionando a sua maior ocorrência com o tempo operatório e a duração da instrumentação.

Numa análise sobre a incidência, prevalência e fatores de risco para infecção no sítio cirúrgico nas cirurgias vertebrais em adultos, Pull ter Gunne e Cohen ${ }^{16}$. encontraram correlação positiva com o maior tempo operatório e justificaram a maior taxa de infecção devido ao maior período de retração tecidual, o que resultaria em isquemia e necrose, aumentando o risco de contaminação. Em outro trabalho desses autores, no qual analisaram os riscos de infecção no sítio cirúrgico nas cirurgias de deformidades vertebrais, o maior tempo operatório correlacionou-se à infecção devido ao maior número de níveis envolvidos na artrodese vertebral e à maior perda de sangue, correlações estas observadas também por outros autores ${ }^{12,13,16,17}$.

Neste estudo realizamos a verificação da presença de bacterioscopia positiva e cultura na primeira, segunda e terceira hora de cirurgia, devido ao nosso tempo cirúrgico médio ser de duas horas e trinta minutos. Devido a este fator muitos pacientes deixaram de ser analisados na terceira hora do procedimento, mas acreditamos que possa haver um crescimento progressivo em cirurgias de maior duração.

Em nossa amostra observamos, nas duas primeiras horas, uma crescente positividade nos resultados da bacterioscopia de acordo com o prolongamento do tempo cirúrgico. Porém, na terceira hora, diferentemente do que esperávamos, observamos uma diminuição da positividade do crescimento bacteriano. Este resultado pode ter sido influenciado pela realização de lavagem da ferida operatória após a segunda hora de cirurgia.

Entretanto, os resultados de cultura, por sua vez, apresentaram a crescente positividade esperada de acordo com o aumento do tempo do procedimento operatório.

Observamos ainda, que os organismos mais comuns envolvidos na cultura positiva foram os estafilococos. Estes resultados também foram encontrados por Fang et al. ${ }^{17}$, quando analisaram os fatores de risco para infecção após cirurgia espinhal, e Sponseller et al. $^{20}$, num estudo sobre infecções após cirurgia de escoliose neuromuscular.

Contudo, os nossos resultados demonstraram que existe uma contaminação da ferida operatória durante o ato cirúrgico e que com o prolongar da cirurgia ocorre o crescimento bacteriano através da cultura de tecido ósseo, demonstrando assim que o tempo cirúrgico prolongado pode ser decisivo no que se refere à taxa de infecção operatória.

\section{CONCLUSÃO}

O tempo cirúrgico prolongado está diretamente relacionado à ocorrência de crescimento bacteriano do sítio cirúrgico, tendo em vista a crescente positividade da bacteroscopia entre a primeira, segunda e terceira hora de cirurgia e a confirmação da colonização da ferida operatória através de cultura.

\section{REFERÊNCIAS}

1. Stokes IA. Three-dimensional terminology of spinal deformity. A report presented to the Scoliosis Research Society by the Scoliosis Research Society Working Group on 3-D terminology of spinal deformity. Spine (Phila Pa 1976). 1994;19(2):236-48.

2. Terry CS. Cirurgia ortopédica de Campbell. 10a. ed. São Paulo: Manole; 2006.

3. Kleinberg S. The operative treatment of scoliosis. Arch Surg. 1922;5:631-45

4. Asher MA, Burton DC. Adolescent idiopathic scoliosis: natural history and long term treatment effects. Scoliosis. 2006;1(1):2.

5. Cowell HR, Hall JN, MacEwen GD. Genetic aspects of idiopathic scoliosis. A Nicholas Andry Award essay, 1970. Clin Orthop Relat Res. 1972;86:121-31.

6. Beals RK. Nosologic and genetic aspects of scoliosis. Clin Orthop Relat Res. 1973;(93):23-32.

7. Moen KY, Nachemson AL. Treatment of scoliosis. An historical perspective. Spine (Phila Pa 1976). 1999;24(24):2570-5

8. Hall JE. Spinal surgery before and after Paul Harrington. Spine (Phila Pa 1976). 1998;23(12):1356-61.

9. Bridwell KH. Surgical treatment of idiopathic adolescent scoliosis. Spine (Phila Pa 1976). 1999;24(24):2607-16.

10. Hawes M. Impact of spine surgery on signs and symptoms of spinal deformity. Pediatr Rehabil. 2006;9(4):318-39.

11. Viola RW, King HA, Adler SM, Wilson CB. Delayed infection after elective spina instrumentation and fusion. A retrospective analysis of eight cases. Spine (Phila Pa 1976). 1997;22(20):2444-50.

12. Pull ter Gunne AF, van Laarhoven CJ, Cohen DB. Incidence of surgical site infection following adult spinal deformity surgery: an analysis of patient risk. Eur Spine J. 2010;19(6):982-8.

13. Olsen MA, Nepple JJ, Riew KD, Lenke LG, Bridwell KH, Mayfield J, et al. Risk factors for surgical site infection following orthopaedic spinal operations. J Bone Joint Surg Am. 2008;90(1):62-9.

14. Bosco JA 3rd, Slover JD, Haas JP. Perioperative strategies for decreasing infection: a comprehensive evidence-based approach. J Bone Joint Surg Am. 2010;92(1):232-9.

15. Ho C, Sucato DJ, Richards BS. Risk factors for the development of delayed infections following posterior spinal fusion and instrumentation in adolescent idiopathic scoliosis patients. Spine (Phila Pa 1976). 2007 Sep 15;32(20):2272-7.

16. Pull ter Gunne AF, Cohen DB. Incidence, prevalence, and analysis of risk factors for surgical site infection following adult spinal surgery. Spine (Phila Pa 1976). 2009;34(13):1422-8.

17. Fang A, Hu SS, Endres N, Bradford DS. Risk factors for infection after spinal surgery. Spine (Phila Pa 1976). 2005;30(12):1460-5

18. Pittet D, Ducel G. Infectious risk factors related to operating rooms. Infect Control Hosp Epidemiol. 1994;15(7):456-62.

19. Weiss HR, Goodall D. Rate of complications in scoliosis surgery - a systematic review of the Pub Med literature. Scoliosis. 2008;3:9.

20. Sponseller PD, LaPorte DM, Hungerford MW, Eck K, Bridwell KH, Lenke LG. Deep wound infections after neuromuscular scoliosis surgery: a multicenter study of risk factors and treatment outcomes. Spine (Phila Pa 1976). 2000;25(19):2461-6. 